\title{
Toxoplasmosis: an examination of knowledge among health professionals and pregnant women in a municipality of the State of Paraná
}

\author{
Ana Paula Contiero-Toninato ${ }^{[1]}$, Helenara Osorio Cavalli ${ }^{[1]}$, Ariella Andrade Marchioro ${ }^{[2]}$, \\ Érika Cristina Ferreira ${ }^{[3]}$, Marcela Caleffi da Costa Lima Caniatti ${ }^{[4]}$, \\ Regina Mitsuka Breganó ${ }^{[5]}$, Italmar Navarro ${ }^{[6]}$ \\ and Ana Lucia Falavigna-Guilherme ${ }^{[4]}$
}

[1]. Hospital Universitário de Cascavel, Universidade Estadual Oeste do Paraná, Cascavel, PR. [2]. Laboratório de Parasitologia Básica, Universidade Estadual de Maringá, Maringá, PR. [3]. Departamento de Estatística, Universidade Estadual de Maringá, Maringá, PR. [4]. Departamento de Ciências Básicas da Saúde, Universidade Estadual de Maringá, Maringá, PR. [5]. Departamento de Ciências Patológicas, Universidade Estadual de Maringá, Maringá, PR. [6]. Departamento de Medicina Veterinária Preventiva, Centro de Ciências Agrárias, Universidade Estadual de Maringá, Maringá, PR.

\begin{abstract}
Introduction: The aim of this study was to investigate the knowledge of toxoplasmosis among professionals and pregnant women in the public health services in Paraná, Brazil. Methods: A cross-sectional observational and transversal study of 80 health professionals (44 nurses and 36 physicians) and 330 pregnant women [111 immunoglobulin M (IgM)- and IgG-non-reactive and 219 IgG-reactive] was conducted in 2010. An epidemiological data questionnaire was administered to the professionals and to the pregnant women, and a questionnaire about the clinical aspects and laboratory diagnosis of toxoplasmosis was administered to the professionals. Results: The participants frequently provided correct responses about prophylactic measures. Regarding the clinical and laboratory aspects, the physicians provided more correct responses and discussed toxoplasmosis with the pregnant women. The professionals had difficulty interpreting the avidity test results, and the physicians stated that they referred pregnant women with high-risk pregnancies to a county reference center. Of the professionals, $53(91.4 \%)$ reported that they instructed women during prenatal care, but only 54 (48.6\%) at-risk pregnant women and $99(45.2 \%)$ women who were not at risk reported receiving information about preventive measures. The physicians provided verbal instructions to $120(78.4 \%)$ women, although instructional materials were available in the county. The pregnant women generally lacked knowledge about preventive measures for congenital toxoplasmosis, but the at-risk pregnant women tended to respond correctly. Conclusions: This study provides data to direct public health policies regarding the importance of updating the knowledge of primary care professionals. Mechanisms should be developed to increase public knowledge because prophylactic strategies are important for preventing congenital toxoplasmosis.
\end{abstract}

Keywords: Health professional. Congenital toxoplasmosis. Pregnant women. Prenatal. Permanent effective control.

\section{INTRODUCTION}

Toxoplasmosis is a zoonosis with worldwide distribution. It is caused by the obligatory intracellular protozoan Toxoplasma gondii ${ }^{1}$. It is transmitted to humans through the ingestion of oocysts shed in the feces of felids, which contaminate water, soil, and food, and by ingesting cysts in meat, viscera, and animal byproducts. It can also be triggered by tachyzoites, which may infect the fetus during pregnancy via the placenta and cause congenital toxoplasmosis².

Address to: Drª Ariella Andrade Marchioro. Laboratório de Parasitologia Básica/UEM. Av. Colombo 5790, Bloco I-90, Sala 07, Zona 07, 87020-900 Maringá, PR, Brasil.

Phone: 5544 3011-8987; Fax: 5544 3011-4860

e-mail: ariella 86@hotmail.com

Received 29 January 2014

Accepted 12 April 2014
During pregnancy, primary infection by $T$. gondii, which is usually asymptomatic for women, can severely affect the fetus (e.g., hydrocephalus, cerebral calcifications, mental retardation, chorioretinitis, microphthalmia, strabismus, deafness, and intrauterine death $)^{3}$. This damage is directly related to the virulence of the parasite, the immune response of the mother, and the gestational age at which the infection is acquired ${ }^{2}$. The population of $T$. gondii in Brazil is highly diverse, with a few successful clonal lineages that have expanded into wide geographical areas, in contrast to North America and Europe, where the Type II clonal lineage is overwhelmingly predominant. In South America, ocular involvement in congenital toxoplasmosis is more frequent than in other locations around the world ${ }^{4}$. Carneiro et al. ${ }^{5}$ indicated that a significant proportion of congenital toxoplasmosis cases $(62.5 \%, 15 / 24)$ was caused by $T$. gondii genotypes that were previously reported in animals.

Strategies for controlling congenital toxoplasmosis are divided into primary, secondary, and tertiary types. Primary 
prevention consists of health education for seronegative pregnant women to prevent maternal infection. The goal of secondary prevention is the early detection of toxoplasmosis through serological screening to identify and treat acute infection during pregnancy and to reduce maternal-fetal transmission or severe sequelae in infants 6 . Tertiary prevention, which is not always possible, consists of the intrauterine detection of toxoplasma infection, neonatal diagnosis, and treatment administered as soon as possible to reduce the severity of sequelae ${ }^{3}$.

Primary prevention is the most effective measure to prevent congenital toxoplasmosis. In Belgium, where prevention has been well applied, maternal seroconversion has been reduced by $60.3 \%$. Different strategies to control toxoplasmosis in the primary and secondary care of pregnant women who are seronegative or who are suspected to be in the acute phase of toxoplasmosis have been used in several countries ${ }^{2,7}$. In France, the prevalence of toxoplasmosis in pregnant women was reduced after implementing control programs that were strategically aimed at seronegative pregnant women ${ }^{8}$. Brazil, however, still faces several challenges in preventing toxoplasmosis in seronegative pregnant women because of the country's vast territory, implementation difficulties, and several epidemiological factors, habits, and cultures among the various regions of the country, as well as the systematization of educational measures among health professionals and pregnant women and the different genotypes that circulate in the country. In 2008, measures were taken by the Brazilian Toxoplasmosis Research Network to coordinate research and improve communication among health services for congenital and ocular toxoplasmosis. This network is still in an early stage of development, but it aims to provide information on congenital toxoplasmosis, epidemiological knowledge, tools, and laboratories in an attempt to implement a variety of control measures, including epidemiological surveillance 9 .

Considering that control strategies must be adapted to local health policies ${ }^{9}$, in August, 2007, Cascavel county in the State of Paraná in southern Brazil started a program to prevent and treat congenital toxoplasmosis through public health services, which began referring immunoglobulin $\mathrm{M}$ (IgM)and immunoglobulin $\mathrm{G}(\mathrm{IgG})$-reactive pregnant women to a center for the care of high-risk pregnant women. Seronegative pregnant women should receive monthly information in Basic Health Units (BHUs), and instructional materials (brochures, posters, booklets, and DVDs) should be provided by physicians and nurses who care for pregnant women. Between August and December, 2007, members of a toxoplasmosis research group at the Universidade Estadual de Londrina, State of Paraná, trained these professionals in three meetings. Note that the turnover of public service professionals in the county is high, although this county specifically focuses on pregnancy and on controlling congenital toxoplasmosis. Regardless of whether the source of the professionals' current knowledge was attributed to program's implementation or to other sources, the objective of the present study was to evaluate the knowledge of toxoplasmosis among healthcare professionals and pregnant women who were being treated in public health services.

\section{METHODS}

\section{Study area}

Cascavel county is located in western Paraná, at 24 57'19.62'S and $53^{\circ} 27^{\prime} 18.85^{\prime \prime} \mathrm{W}$, and it has a population of approximately $286,172^{10}$. The county has 33 BHUs and an average of 4,000 births/year; approximately 3,000 pregnant women receive prenatal care in these BHUs ${ }^{11}$.

\section{Assessing the preventive measures and activities for controlling congenital toxoplasmosis}

A cross-sectional observational and transversal study of health professionals who provided prenatal care to the pregnant women who were treated in 33 BHUs was conducted from March to November, 2010. The same questionnaire was used for both physicians and nurses; it included questions about clinical, laboratory, and epidemiological data.

The appropriate sample size of pregnant women was determined using the estimate of 3,000 pregnant women who were treated each year in a BHU. With an expected 50\% prevalence of exposure to $T$. gondii and a desired significance level of $5 \%$, we calculated that we would need a sample size of 330 pregnant women. The questionnaire, which included questions about epidemiological aspects of toxoplasmosis transmission, was used in the maternity ward of the University Hospital on the second day after delivery and was administered only to women who lived in the county and who had live births. We excluded the patients who received prenatal care in other counties or at private clinics, patients with stillbirths or abortions, and patients who refused study participation.

The pregnant women were divided into two groups (i.e., susceptible and non-susceptible to toxoplasmosis), according to the results of anti- $T$. gondii serological tests performed during prenatal care. Susceptible women were considered to be those with IgM- and IgG-non-reactive serology, and non-susceptible women were considered to be those with IgG-reactive serology.

Additional data, including the start date of prenatal care and the dates and number of serological tests for toxoplasmosis, were obtained from the medical and prenatal records for each woman.

\section{Statistical analysis}

The data were compiled in Microsoft Excel 2010 spreadsheets and statistically analyzed using SAS 9.1 software (Statistical Analysis System) version 9.1 (Cary, North Carolina, USA). Fisher's exact test was used to evaluate the possible associations, and the level of significance for all tests was $5 \%$.

\section{Ethical considerations}

The Research Ethics Committee from the State University of Maringá approved the study (protocol number 575/2009). All participants provided signed informed form. 


\section{RESULTS}

Of the 80 professionals (44 nurses and 36 physicians) who worked in the BHU the Cascavel, 58 (72.5\%) agreed to participate in the study: $36(81.8 \%)$ nurses and $22(61.1 \%)$ physicians. Of the 58 professionals interviewed, $100 \%$ of the physicians and $63.9 \%$ of the nurses, reported knowing about the county's toxoplasmosis pregnancy prevention program. Among the professionals, eight (36.4\%) physicians and six (16.7\%) nurses reported that they had attended training workshops in 2007. However, the physicians and nurses had difficulty interpreting avidity test data and difficulty recognizing the tool's importance, particularly during the first trimester of a pregnancy (Table 1). The physicians reported the importance of using the county's specialized center to monitor pregnant women who were suspected of being acute cases. Both the physicians and the nurses recognized that the risk of congenital transmission increases with the gestational trimester (Table 1).

Among the professionals, 94.8\% (55) recognized that a pregnant woman with IgM- and IgG-non-reactive serology must be instructed about preventive measures for toxoplasmosis and should repeat the serological test in each trimester. Physicians displayed increased knowledge about the transmission risks associated with gestational age and about the need to refer pregnant women who are suspected of acute disease to the reference center for high-risk pregnancies in the county
(Table 1). Thus, regarding knowledge about the clinical and laboratory aspects of the disease, these professionals displayed increased knowledge (i.e., increased ORs), despite their difficulties in interpreting the avidity test results (Table 1). Regarding the principal preventive measures for toxoplasmosis, the physicians and nurses correctly identified the alternatives (Table 2). The measures most often mentioned by professionals were washing the utensils (e.g., knives and cutting boards) used to prepare meat, eating well-performed meat, washing hands, or using gloves when handling soil or sand, and taking special care with cat stool (Table 2). Of the professionals, 91.4\% (53) said that they instructed women during prenatal care.

Among the pregnant women, there was a lack of knowledge about preventive measures for congenital toxoplasmosis among both susceptible and seroreactive individuals (Table 3). The principal correct responses were taking care of cat stool, eating well-performed meats, washing fruits and vegetables before consumption, and washing hands or using gloves when handling soil or sand (Table 3).

Only $48.6 \%$ (54) of the susceptible pregnant women and $45.2 \%$ (99) of the non-susceptible women reported that they had received information about the preventive measures for toxoplasmosis during prenatal care. For both groups, the primary form of instruction was verbal $(78.4 \%, 120)$, followed by group lectures $(15.7 \%, 24)$ and informational pamphlets $(9.8 \%, 15)$. None of the women mentioned receiving instructions from educational videos. Most of the women received information

TABLE 1 - Knowledge among the BHU professionals concerning toxoplasmosis and the procedures used for pregnant women in southern Brazil.

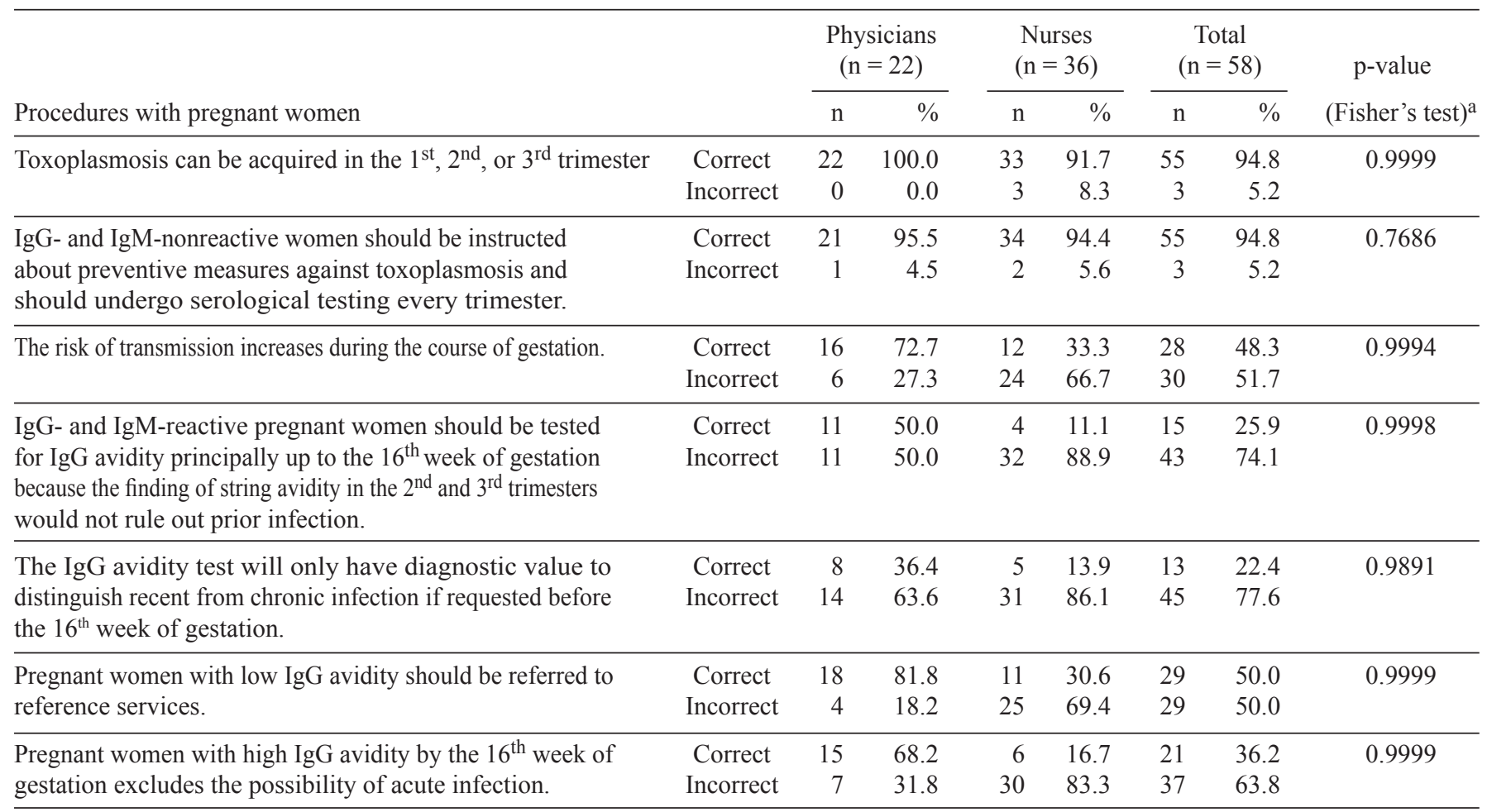

BHU: Basic Health Units; IgM: immunoglobulin M; IgG: immunoglobulin G. aFisher's test: no association revealed significant differences. 
TABLE 2 - Knowledge among BHU professionals concerning the preventive measures for toxoplasmosis in southern Brazil.

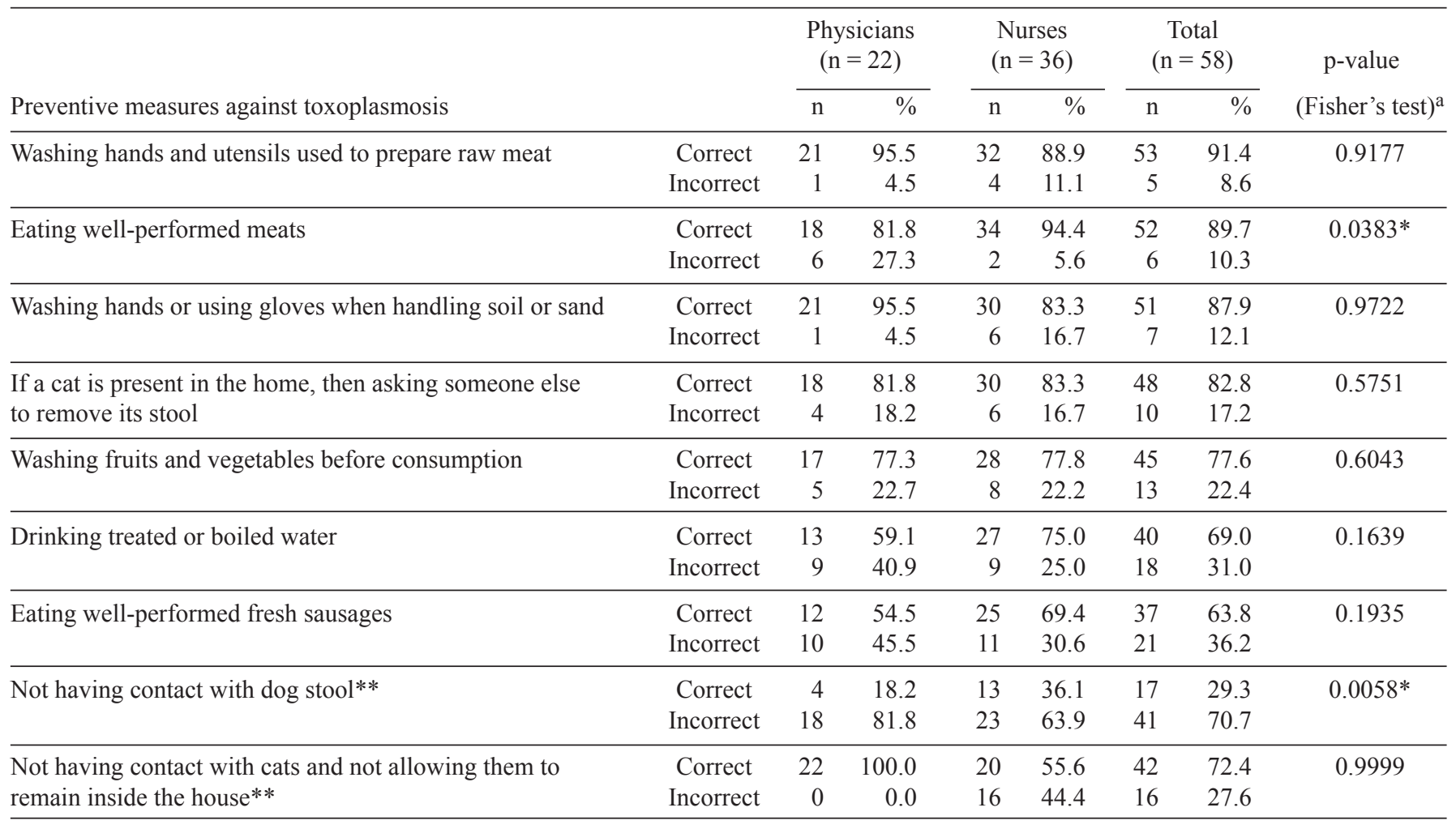

BHU: Basic Health Units. ${ }^{\mathrm{a} F i s h e r ' s ~ t e s t: ~ * a s s o c i a t i o n s ~ w e r e ~ c o n s i d e r e d ~ s i g n i f i c a n t . ~ * * M e a s u r e s ~ n o t ~ r e c o m m e n d e d ~ t o ~ p r e v e n t ~ t o x o p l a s m o s i s . ~}$

TABLE 3 - Knowledge among susceptible and non-susceptible postpartum women treated at BHUs concerning the preventive measures for toxoplasmosis in the Municipality of Cascavel, State of Paraná, from March to November, 2010.

\begin{tabular}{|c|c|c|c|c|c|c|c|c|}
\hline \multirow[b]{2}{*}{ Preventive measures against toxoplasmosis } & & \multicolumn{2}{|c|}{$\begin{array}{l}\text { Susceptible } \\
(\mathrm{n}=111)\end{array}$} & \multicolumn{2}{|c|}{$\begin{array}{l}\text { Non-susceptible } \\
\quad(\mathrm{n}=219)\end{array}$} & \multicolumn{2}{|c|}{$\begin{array}{c}\text { Total } \\
(\mathrm{n}=330)\end{array}$} & \multirow{2}{*}{$\begin{array}{l}\text { p-value } \\
\text { (Fisher's test) }^{\mathrm{a}}\end{array}$} \\
\hline & & $\mathrm{n}$ & $\%$ & $\mathrm{n}$ & $\%$ & $\mathrm{n}$ & $\%$ & \\
\hline $\begin{array}{l}\text { If a cat is present in the home, then asking someone else to } \\
\text { remove its stool }\end{array}$ & Incorrect & 63 & 56.8 & 169 & 77.2 & 232 & 70.3 & 0.9999 \\
\hline Eating well-performed meats & Correct & 42 & 37.8 & 53 & 24.2 & 95 & 28.8 & 0.9964 \\
\hline \multirow[t]{2}{*}{ Washing fruits and vegetables before consumption } & Correct & 42 & 37.8 & 51 & 23.3 & 93 & 28.2 & \multirow[t]{2}{*}{0.9980} \\
\hline & Incorrect & 69 & 62.2 & 168 & 76.7 & 237 & 71.8 & \\
\hline \multirow[t]{2}{*}{ Washing hands or using gloves when handling soil or sand } & Correct & 33 & 29.7 & 39 & 17.8 & 72 & 21.8 & \multirow[t]{2}{*}{0.9951} \\
\hline & Incorrect & 78 & 70.3 & 180 & 82.2 & 258 & 78.2 & \\
\hline Drinking only treated or boiled water & Correct & 18 & 16.2 & 38 & 17.4 & 56 & 17.0 & 0.4629 \\
\hline \multirow[t]{2}{*}{ Not having contact with dog stool* } & Correct & 34 & 30.6 & 61 & 27.9 & 95 & 28.8 & \multirow[t]{2}{*}{0.7448} \\
\hline & Incorrect & 77 & 69.4 & 158 & 72.1 & 235 & 71.2 & \\
\hline \multirow{2}{*}{$\begin{array}{l}\text { Not having contact with cats, not allowing them to remain } \\
\text { inside the house* }\end{array}$} & Correct & 67 & 60.4 & 112 & 51.1 & 179 & 54.2 & \multirow[t]{2}{*}{0.9562} \\
\hline & Incorrect & 44 & 39.6 & 107 & 48.9 & 151 & 45.8 & \\
\hline \multirow[t]{2}{*}{ Reported not being aware of any measure } & Correct & 100 & 90.1 & 130 & 59.4 & 230 & 69.7 & \multirow[t]{2}{*}{0.9999} \\
\hline & Incorrect & 11 & 9.9 & 89 & 40.6 & 100 & 30.3 & \\
\hline
\end{tabular}

BHU: Basic Health Units. ${ }^{\text {a}}$ Fisher's test: no association revealed significant differences. ${ }^{*}$ Measures not recommended to prevent toxoplasmosis. 
from their physicians $(70.6 \%, 108)$, followed by nurses $(22.9 \%, 35)$, community health workers $(17.6 \%, 27)$, and nursing assistants and technicians $(8.5 \%, 13)$.

Of the 330 pregnant women in the study, $63.9 \%$ (211) started prenatal care during the first trimester of pregnancy, 32.4\% (107) started prenatal care in the second trimester, and 3.6\% (12) started prenatal care in the third trimester; $99.1 \%$ (277) of the women underwent prenatal screening for toxoplasmosis. The first serological test was performed in the first trimester for $58.8 \%$ (194) of the women, and $65.1 \%$ (215) repeated the test at least once. The serological results indicated that $33.6 \%$ (111) were susceptible to toxoplasmosis, and $66.4 \%$ (219) were non-susceptible.

\section{DISCUSSION}

The present results indicate that although the professionals had considerable knowledge about how to control toxoplasmosis, in the public health services that were studied, the pregnant in the same service women lacked knowledge, although the seronegative women provided a greater number of correct responses on topics related to the principal control measures and to health. This study was conducted in an area of Brazil in which a program had already been implemented to control congenital toxoplasmosis during pregnancy. Nevertheless, the data revealed the importance of continuing health education programs, both for the patients and for the professionals who must provide this education. The present results are superior to those reported in another region of Paraná where a suitable control program has not yet been established ${ }^{12}$. The health professionals (physicians and nurses) who worked directly with the pregnant women in this community had little knowledge about this zoonotic disease and its complications, and seronegative pregnant women were not informed about the methods to prevent exposure to toxoplasmosis ${ }^{12}$.

The nurses in this study displayed less knowledge the doctors about the clinical aspects and laboratory results of toxoplasmosis in pregnant women; this deficiency could be remedied with education courses about this zoonotic disease. Notably, these professionals spent more time in public health units. Thus, it would be useful to promote educational activities for pregnant women, in the public health units with periodic meetings, instructional materials, scheduling, and monitoring of clinical and laboratory outcomes among other professionals. Primary prevention in public health involves messages that are transmitted repeatedly to the public, using a variety of educational resources at different time points. To encourage the adoption of healthy behaviors, the use of only one educational resource is insufficient ${ }^{13}$. Because of the importance of educational materials, the health secretariat of the county acquired flyers, posters, and educational films for use in the $\mathrm{BHU}^{14}$, but these materials were not available in all units during the study period.

BHU physicians were the professional group that provided the most information to pregnant women over the course of their prenatal care. However, some aspects of this program could be improved, such as providing more accurate information, if this is your intended meaning to pregnant women who are suspected of having acute toxoplasmosis and improving the level of physicians' knowledge about the IgG avidity test. If performed in the first trimester, this test aids in patient diagnosis and, thus, also aids in the implementation of appropriate treatment strategies for pregnant women ${ }^{15}$. Although most of the physicians studied did not know how to properly interpret the test results with respect to gestational age, most of the physicians still referred the pregnant women with low IgG avidity to the reference unit. This result reinforces the importance of maintaining reference units within the county or in a cluster of smaller cities to monitor pregnant women with laboratory test results that indicate possible toxoplasmosis to ensure that they can be monitored properly and treated, if necessary ${ }^{16}$.

Health professionals play an important role in advising pregnant women. This study strengthens the case for an integrated network among the BHU health professionals caring for pregnant women.

Only a minority of susceptible pregnant women underwent serological testing in each trimester. Nearly all physicians stated that it was necessary to repeat serological testing in each trimester for the susceptible pregnant women. Only half of the susceptible women reported that they received information (mainly verbally) about toxoplasmosis during the prenatal period. Carellos et al. ${ }^{17}$ obtained similar results in Belo Horizonte, where $54.6 \%$ of susceptible pregnant women stated that they had received prenatal advice, most (98\%) of which was given verbally.

Among the professionals and pregnant women who correctly responded about control measures, there was a lack of knowledge about the strict association between $T$. gondii contamination and cat feces, the presence of a cat in the home, food derived from animals, fruits, and vegetables, as well as contact with soil. Generally, toxoplasmosis is still strongly associated with the presence of a cat in the home ${ }^{18-22}$.

A lack of time or interest on the part of health professionals may negatively influence educational programs ${ }^{23}$. In Brazil, the significant turnover of these professionals, particularly physicians, hinders their involvement in training, meetings, and events. This turnover may explain the low proportion of professionals who reported that they had participated in training workshops on toxoplasmosis during the implementation process in the county. Given the complexity of diagnosis, treatment, and measures to be adopted in cases of gestational toxoplasmosis in different geographic areas, periodic continuing education is justified to guarantee the quality of care for pregnant women and to meet the program goals, which seek to prevent and treat toxoplasmosis. The implementation of toxoplasmosis control programs is intensifying with continuing education programs for professionals, particularly because of the high turnover of these professionals and to better enable these professionals to utilize the strategies and educational resources that are available in the county to help prevent and improve the treatment of toxoplasmosis. 
The present study encourages public health policies to consider the importance of updating the knowledge of primary care professionals as advances in scientific knowledge become available. Mechanisms should exist to facilitate the transfer of knowledge to patients, particularly considering that prophylactic strategies are central in preventing congenital toxoplasmosis.

\section{CONFLICT OF INTEREST}

The authors declare that there is no conflict of interest.

\section{FINANCIAL SUPPORT}

Financial support for this study was received from $\mathrm{CNPq}$ and Fundação Araucária, Brazil.

\section{REFERENCES}

1. Nicolle C, Manceaux L. Sur une infection à corps de Leishmman (our organisms voisins) du dondi. C R Hebd Séance Acad Sci Paris 1908; 147:763-766.

2. Desmonts G, Couvreur J. Congenital toxoplasmosis. A prospective study of 378 pregnancies. N Engl J Med 1974; 20: 1110-1116.

3. Remington JS, Mcleod R, Thulliez P, Desmonts G. Toxoplasmosis. In: Remington JS, Klein JO, editors. Infectious disease of the fetus and newborn infant. $6^{\text {th }}$ ed. Philadelphia: Elsevier Saunders 2006; p. 947-1091

4. Melamed J, Eckert GU, Spadoni VS, Lago EG, Uberti F. Ocular manifestations of congenital toxoplasmosis. Eye (London) 2010; 24: 528-534.

5. Carneiro ACAV, Andrade GM, Costa JGL, Pinheiro BV, Vasconcelos-Santos DV, Ferreira AM, et al. Genetic characterization of Toxoplasma gondii revealed highly diverse genotypes for isolates from newborns with congenital toxoplasmosis in southeastern Brazil. Clinical Microbiol 2013; 51:901.

6. Foulon W, Naessens A, Derde MP. Evaluation of the possibilities for preventing congenital toxoplasmosis. Amer J Perinatol 1994; 11:57-62.

7. Joynson $\mathrm{D}$, Wreghitt $\mathrm{T}$. Toxoplasmosis. A comprehensive clinical guide: Sous la direction de D.H.M. Joynson et T.G. Wreghitt Cambridge: Cambridge University Press; 2001.

8. Villena I, Ancelle T, Delmas C, Garcia P, Brézin AP, Thulliez P, et al. Congenital toxoplasmosis in France in 2007: first results from a national surveillance system. Surveillance and outbreak reports; 2010.
9. Lago EG. Rede Brasileira de Toxoplasmose. Carta de Búzios: Proposta para o controle da toxoplasmose no Brasil. Sci Med 2010; 20:5-8.

10. Instituto Brasileiro de Geografia e Estatística (IBGE) [Internet]. Rio de Janeiro: IBGE; 2010. [cited 2010 Mar 21]. Available at: http://www.ibge.gov.br/home/estatistica/populacao/censo2010/tabelas

11. Municipal Health Department of Health Surveillance of Cascavel. Cascavel, Paraná; 2010.

12. Branco BHM, Araújo SM, Falavigna-Guilherme AL. Prevenção primária da toxoplasmose: conhecimento e atitudes de profissionais de saúde e gestantes do serviço público de Maringá, estado do Paraná. Sci Med (Porto Alegre) 2012; 22:185-190.

13. Dabritz HA, Conrad PA. Evaluation of an educational handout on knowledge about toxoplasmosis. Sci Med (Porto Alegre) 2010; 20: 51-58.

14. Mitsuka-breganó R, Lopes-Mori FMR, Navarro IT. Toxoplasmose adquirida na gestação e congênita. Vigilância em saúde, diagnóstico, tratamento e condutas, Londrina: Eduel; 2010.

15. Araújo PRB, Ferreira AW. Avidity of IgG antibodies against excreted/ secreted antigens of Toxoplasma gondii: immunological marker for acute recent toxoplasmosis. Rev Soc Bras Med Trop 2008; 41:142-147.

16. Higa LT, Araújo SM, Tsuneto L, Castilho-Peloso M, Garcia JL, Santana RG, et al. A prospective study of Toxoplasma-positive pregnant women in southern Brazil: a health alert. Trans R Soc Trop Med Hyg 2010; 104: 400-405.

17. Carellos EVM, Andrade GMQ, Aguiar RALP. Avaliação da aplicação do protocolo de triagem pré-natal para toxoplasmose em Belo Horizonte, Minas Gerais, Brasil: Estudo transversal em puérperas de duas maternidades. Cad Saúde Pública (Rio de Janeiro) 2008; 24:391-401.

18. Milar PR, Daguer H, Vicente RT, Costa T, Sobreiro LG, Amendoeira MR. Toxoplasma gondii: estudo soro-epidemiológico de suínos da região Sudoeste do Estado do Paraná. Pesq Vet Bras 2008; 28:15-18.

19. Moura L, Bahia-Oliveira LMG, Wada MY, Jones J, Tuboi S.H, Carmo EH, et. al. Waterborne Toxoplasmosis, Brazil, from field to gene. Emerg Infect Dis 2006; 12: 326-329.

20. Ogawa L, Navarro IT, Freire RL, Oliveira RC, Vidotto O. Ocorrência de anticorpos anti-Toxoplasma gondii em ovinos da região de Londrina no Estado do Paraná, Brasil. Semina Ciênc Agrar Londrina 2003; 24:57-62.

21. Petersen E, Vesco G, Villari S. What Do We Know About Risk Factors for Infection in Humans with Toxoplasma gondii and How Can We Prevent Infections? Zoonoses Public Health 2010; 57:8-17.

22. Reis CR, Lopes FMR, Gonçalves DD, Freire RL, Garcia JL, Navarro IT. Occurrence of anti-Toxoplasma gondii antibodies in caprines from Pitanga City, Paraná State, Brazil. Braz J Vet Res Anim Sci 2007; 44:358-363.

23. Pawlowski ZS, Gromadecka-Sutkiewicz M, Skommer J, Paul M, Rokossowski H, Suchocka E, et al. Impact of health education on knowledge and preventions behavior for congenital toxoplasmosis: The experience in Poznan, Poland. Health Educ Res 2001; 16:493-502. 